\section{Applications for Membership}

The WTSA is now accepting Applications for Membership online for Active as well as Candidate membership status. Visit the WTSA Web site at www.westernthoracic.org to read the complete membership eligibility requirements and to initiate an online application.

\section{Active Member}

$\$ 325.00$ annually, plus $\$ 50.00$ initiation fee

Applicant must meet all membership criteria, including but not limited to:

- Reside within or have completed a cardiothoracic residency training program within the geographic limits of the Association.

- Have been engaged in the practice of thoracic and cardiovascular surgery for at least three years following completion of postgraduate training. If a candidate completed his/her thoracic surgical residency in an institution within the geographic limits of the Association, such completion may count towards one of the three years of practice.

- Have a full and unrestricted license to practice medicine in his or her respective state or province, and have a current appointment on the surgical staff of a hospital with no reportable action pending that could adversely affect such applicant's staff privileges at any hospital.

\section{Candidate Member}

$\$ 100.00$ annually

Applicant must meet all membership criteria, including but not limited to:
- Be matched or enrolled in either a cardiothoracic surgery education program accredited by the Residency Review Committee for Thoracic Surgery under the authority of the ACGME or a program approved for cardiothoracic surgery education by the Royal College of Surgeons of Canada-or their equivalency-from within the Association's geographic limits. Individuals who have completed their education in one of the above programs and are in the process of acquiring certification in cardiothoracic surgery by either the American Board of Thoracic Surgery or the Royal College of Surgeons of Canada also are eligible to apply for Candidate membership. Individuals who trained outside the Association's geographic limits who are now residing within the Association's boundaries but do not yet have three years in practice also are eligible to apply for Candidate membership.

An application must include the following uploads: a photo, a complete curriculum vitae with bibliography, and, for Active applicants, his/her 3 most significant articles. The application must be completed and submitted online by March 1, 2015, and all support letter(s) (three for Active applicants, one for Candidates) uploaded by that applicant's sponsor(s) by March 31, 2015, in order for the applicant to be considered for election to membership at the 2015 Annual Meeting.

\section{WTSA 41st Annual Meeting}

Save the Date!

June 24-27, 2015

Fairmont Chateau Whistler

Whistler, British Columbia, Canada

\section{The AATS Graham Foundation}

\section{In Its 41st Year, the AATS Graham Foundation Announces New Specialty Programs}

Over the past year, new fellowship programs for international professionals, fellows, residents, and medical students have been developed that provide specialized educational and training opportunities.

The Cardiothoracic Surgical Investigator Program caters to cardiothoracic surgeons interested in conducting clinical or translational research, while the Traveling Scholar Program provides young cardiothoracic surgeons from around the world a chance to study clinical techniques at a secondary institution.

Our new Resident Poster Session Scholarship for thoracic surgical residents has become extremely popular and competitive, along with the Critical Care Scholarship program that boasts over 50 students expected to participate in 2014 !
The AATS Graham Foundation Fellowship for Advanced EBUS Training Program (sponsored by Olympus America) provides an educational experience for young thoracic surgeons from North America to spend a focused period of between one month and four months' time studying clinical techniques at a host institution proficient in EBUS. The AATS Graham Foundation Intuitive Surgical Robotics Fellowship provided an advanced educational experience for 8 North American general thoracic Fellows and their attending surgeons to spend a two-day period at Intuitive Surgical's Atlanta, GA, facility to experience an introductory training course on Intuitive Surgical's da Vinci System.

The Honoring our Mentors Fellowship program, initially honoring F. Griffith Pearson, enables North American surgeons who have recently completed their residency in general thoracic surgery to spend a focused period of four (4) to six (6) weeks' time studying clinical techniques at a host institution in North America. 
Since our parent Association, the AATS, underwrites all operational costs of the Foundation, $100 \%$ of all individuals' contributions to go directly to Foundation programming. The AATS Graham Research Foundation is driving leadership, learning, and innovation in the pursuit of excellence!

For more information on the AATS Graham Foundation, please visit http://aatsgrahamfoundation.org.

\section{Edwards Lifesciences Advanced Treatments of Valve Disease Fellowship}

The Edwards Lifesciences Advanced Treatments of Valve Disease Fellowship provides an educational experience for a young cardiothoracic surgeon to spend a period of three months (minimum) to one year studying clinical techniques at a secondary institution with a focus on enhancing expertise in advanced treatments of valve disease. A $\$ 25,000$ award will be provided to a successful applicant to help defray related travel and living expenses incurred at the secondary institution.

For additional information regarding the Fellowship please visit the AATS Graham Foundation Web site at www.AATSGrahamFoundation.org. Interested applicants should meet the following qualifications before applying:

- A candidate should have completed his/her formal training in general surgery and in thoracic and/or cardiovascular surgery, but should yet not have reached a senior position.

- Candidate meets all necessary criteria (license, visa, etc) for travel to and from secondary center

- Candidates must have a current academic or hospital appointment

- Candidates must be in their first five years after CT training

Applications for consideration must be submitted electronically by November 1, 2014. Applications will be reviewed by the AATS Graham Foundation's Scientific Review Committee, which includes surgeons with recognized expertise in the treatment of valve disease. Applications will be graded on all aspects of the award criteria and notified of the decision by December 15th.

\section{Ethicon Fellowship for Advanced Thoracic Minimally Invasive Surgery}

The AATS Graham Foundation Ethicon Fellowship for Advanced Thoracic MIS provides an educational experience for young thoracic surgeons from the United States to spend a focused period of time between three months and one year time to study clinical techniques at a host institution proficient in MIS. The program is primarily geared to provide an opportunity to obtain expertise in advanced treatments of minimally invasive surgery, such as lung resection surgery.

For additional information regarding the Fellowship, please visit the AATS Graham Foundation Web site at www.AATSGrahamFoundation.org. Interested applicants should meet the following qualifications before applying:

- A candidate should have completed his/her formal training in general surgery and in thoracic and/or cardiovascular surgery, but should yet not have started a staff position or have started a staff position within a 12-month period prior to commencing this fellowship.

- Candidate meets all necessary criteria (license, visa, etc) for travel to and from secondary center

- Candidates must have a current academic or hospital appointment

- Candidates must be in their first five years after thoracic training

\section{Application Process}

Applications will be available annually with a deadline of November 1st. In addition to a formal online application, candidates will also be required to upload the following materials:

- Curriculum vitae

- Letter of support from their home and secondary institutions

- Detailed outline of plans for the duration of stay at secondary center

- One page narrative on what they hope to accomplish during their travel to a secondary training center

- One page statement of future career goals

- One page statement describing the relationship of the planned study to the applicant's prior work, preparation and professional goals

Applications for consideration must be submitted electronically by November 1, 2014. Applications will be reviewed by the AATS Graham Foundation's Scientific Review Committee, which includes surgeons with recognized expertise in minimally invasive surgery and the focus will be to place the recipients in institutions using Ethicon technology for MIS. Notifications of the final decision will be provided by December 15th. 